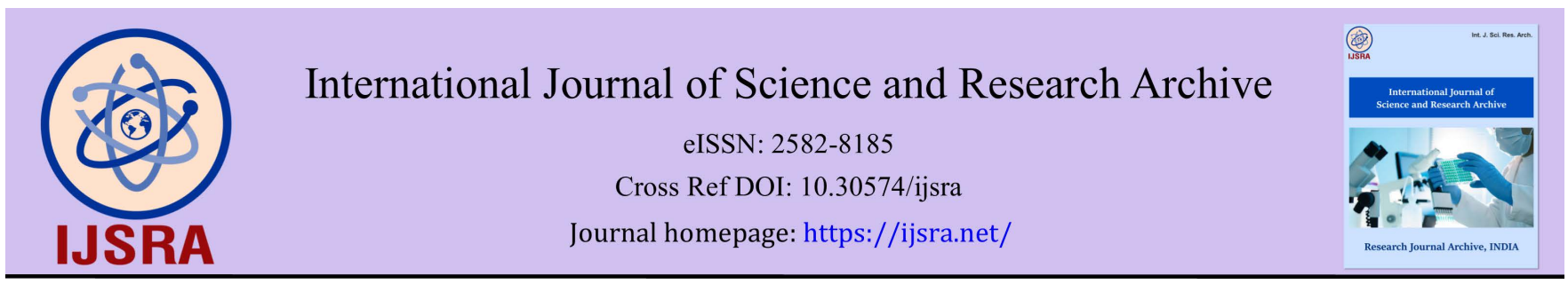

(RESEARCH ARTiClE)

\title{
Effects of chemical mutagen (sodium azide) on tomato grown in organic and inorganic fertilized soil
}

\author{
Olatunde Micheal Adeoti, Zainab Sodiq, Samson Olutope Olufemi and Kafilat Adenike Komolafe \\ Department of Science Laboratory Technology, Environmental Biology Option, The Oke-Ogun Polytechnic, Saki, Oyo State, \\ Nigeria.
}

International Journal of Science and Research Archive, 2021, 02(01), 072-078

Publication history: Received on 07 January 2021; revised on 11 February 2021; accepted on 13 February 2021

Article DOI: https://doi.org/10.30574/ijsra.2021.2.1.0016

\begin{abstract}
Tomato (Lycopersicon esculentum); a member of the family Solanacea is a commercially important vegetable throughout the world both for the fresh fruit market and food industries. The research was carried out in the green house at Science Laboratory Technology of the Oke-Ogun Polytechnic, Saki, Oyo State. Improved dry seeds of tomato (Lycopersicon esculentum) was obtained from the Institute of Agriculture Research, (I.A.R\&T), Ibadan, Oyo State and were subsequently treated with Sodium Azide aimed at determining the effects of Sodium Azide as a known mutagen on tomato grown with organic and inorganic fertilizer. All the parameters were monitored for six-months with everyday documentation of variants (variables). Highly significant differences were observed in the treatments with respect to the studied parameters (seed germination, seedling survival, seedling height, root length, number of leaves per seedlings, height at maturity, number of branches per plant and fruits per plant) and various chemicals found in the soil sample. Treatment and chemical interactions were similarly highly significant in tomato with Sodium Azide and organic fertilizer with respect to all parameters evaluated and the chemical composition showed better performance compared to tomato seeds grown with inorganic fertilizer. Conversely, Sodium Azide could be utilized as an induced of variability for the improvement of tomato likewise organic fertilizers
\end{abstract}

Keywords: Sodium Azide; Chemical mutagen; Induced-mutation; Lycopersicon esculentum, Seedling-survival, Preplanting

\section{Introduction}

Tomato (Lycopersicon esculentum) which belong to the family Solanacea is a commercially important vegetable throughout the world both for the fresh fruit market and food industries. Tomato is an annual fruit vegetable of the tropical region which originated in South and Central America [1]. The Nahuat (Aztec language) word tomata gave rise to the Spanish word tomata, from which the English word tomato derive. Its domestication and use as a cultivated food may have originated from indigenous people of Mexico. Tomato is considered one of the most valuable horticultural crops, not only because of its economic importance, but also for its sensory qualities and nutritional value. It is usually in the form of fresh as well as processed products for consumption. More than $80 \%$ of tomatoes grown throughout the world are processed into products such as sauce, juice, stew and other products [2]. Tomato medicinal properties were approved in continental Europe in the 16th century, [3]. Tomatoes consumption reduces cardiovascular disease and also helps in high blood pressure reduction, a major risk factor for coronary heart disease and stroke to relieve bloodshot eyes. One of the serious challenges facing the global population today is the problem of food insufficiency and low quality standard. Tomato is one of the food crops with the potential to provide vitamins, calcium, protein and agrobased raw materials for the ever increasing global population [3, 4]. [5] Reported the utilization of tomato as food and

\footnotetext{
* Corresponding author: Adeoti O.M.

Department of Science Laboratory Technology, Environmental Biology Option, The Oke-Ogun Polytechnic, Saki, Oyo State, Nigeria. Copyright $(2021$ Author(s) retain the copyright of this article. This article is published under the terms of the Creative Commons Attribution Liscense 4.0.
} 
its other economic purposes. The value and utilization of tomato as a crop for both nutritional and industrial purposes primarily depends upon the quality of its composition. It is however disheartening that despite the significance of tomato to the world (in terms of food and health status of modern man), proper attention in terms of its improvement is lacking [6]

Epidemiological studies have proved the importance of tomato and its products in reducing various ailments because they contain high amounts of antioxidants such as carotenoids, polyphenols, ascorbic acid and many others [7]. Lycopene is the most plentiful carotene in the tomato fruit, comprising up to $90 \%$ of the total carotenoids present [2], and is the most important antioxidant with a high oxygen free radical-scavenging and quenching capacity, and thus provides protection against chronic diseases, such as several types of cancer, including cancer in the mouth, pharynx, esophagus, stomach and large intestine, and cardiovascular diseases [7]. Lycopene is also the pigment mainly responsible for the red colour of tomato fruits. Various studies have reported that the lycopene content in tomatoes is most notably influenced by various genetic and environmental factors, such as the cultivar, growing season, cultivation conditions and harvesting stage [3]. Organic and inorganic fertilizer are known to improve the activities of microorganism in the soil as well improves water movement and good aeration of the soil. Inorganic fertilizers are also been used by farmers in the production of tomatoes and many researchers have documented reports on the increased yield of tomatoes through its application [8]. Among the commonly used inorganic fertilizers by vegetable farmers are the NPK and Urea but the scarcity and high price of these fertilizers remain a challenges facing crop production especially in this region. There is a little or no information available on the effectiveness and efficacy of these fertilizers in the production of tomato. Tomato presents a relatively small genome highly synthetic to others economically important Solanaceae species and was selected as a reference species for sequencing a Solanaceae genome. In addition to the availability of a number of genomic resources, including transcriptome [2] and metabolome, large collections of genetic resources are available to dissect the biochemical and the metabolic pathways in tomato. Large EMS and fast neutron mutant collections, in the background of M-82 tomato cultivars, have been generated and more than 3,000 phenotype alterations catalogued [8].

Tomato is a crop that is very important to human diet. For instance, in Greece, 1.8 million MT were produced. In the Mediterranean area, where land use is very intensive and continuous cropping is in common practice, vegetable grafting is considered an innovative technique with an increasing demand by farmers. Viewing recent data concerning the Mediterranean area by [9] it was reported that Spain is the country that is known for its importance in the spreading of vegetable grafting with mainly tomato and watermelon, with 40 and 52\% of the total of 154 million plants in 2004 , respectively. They also indicated that an increasing dissemination of the grafting technique in Italy increased the number of the grafted vegetable plants from 4 million in 1997 to 14 million in 2000. grafting is becoming highly popular, especially in southern areas of Greece, where the ratio of the production area using grafted plants compare to the total production area, amounts to almost $90-100 \%$ for early cropping watermelons, for melons under low tunnels $40 \%-50 \%$, $5-10 \%$ for cucumbers and $2-3 \%$ for tomato and eggplant.

The prime strategy in mutation-based breeding on the other hand has been to upgrade the well-adapted plant varieties by altering one or two major parameters. These include characters such as plant height, maturity, seed shattering, and disease resistance, which contribute to increased yield and quality parameters, for instance, modified oil profile and content, malting quality, and size and quality of starch granules [9]. However, in many cases, the changed parameters had a synergistic effect on the cultivation of the crop, agronomic inputs, crop rotation and utilization. For instance, the short height genotypes in rice, wheat, barley and maize have contributed significantly to increasing grain yield because of their resistance to lodging and high planting density, high doses of nitrogen is application is also applicable for the short height trait. The early maturity of some mutants resulted in timely planting of the follow-up crop; for example early maturity of cotton in Pakistan allowed early planting of the wheat crop, resulting in higher wheat yield. The induction of thermo-sensitive genic male-sterile mutant in Japonica rice, which is controlled by a single recessive gene [10], contributed significantly to develop strategies for the production of hybrid rice varieties. Similar mutants were induced through gamma irradiations in rice [11]. Such mutants allow production of hybrid seed based on only two lines, and show increased yield from heterosis. Mutation is the underlying cause of evolution as an individual with a novel trait may be preferentially selected for in nature - because its superior fitness arising from novel (mutant) adaptive features - or artificially because of the desirability of traits by man.

Mutations are the tools used by the geneticist to study the nature and functions of genes which are the building blocks and basis of plant growth and development, thereby producing and creating raw materials for genetic improvement of economic crops [11]. Induced mutation has been established as an important tool for improvement of certain parameters in the existing germplasm. Mutation breeding has been used widely for improving plant characters in various crops. It is a powerful and effective tool in the hands of plant breeders especially for autogamous (self- 
fertilizing) crops having narrow genetic base [12]. In any mutation breeding program, selection of an effective and efficient mutagen is very important and essential to produce high frequency of desirable mutation. Many chemical mutagens have been employed for obtaining useful mutants in various crop species [13]. The role of mutation breeding increases the genetic variability for the desired parameters in various crop plants [11]. Variability is indispensable for any breeding program to evolve high yielding varieties with other desirable attributes. In such a situation, induced mutations can be used to generate useful variation in quantitatively inherited characters. Induced mutation using physical and chemical mutagen is a method to create genetic variation resulting in new varieties with better characteristics Sodium Azide $\left(\mathrm{NaN}_{3}\right)$ is a chemical mutagen and which considers as one of the most powerful mutagens in plants. Its application on plant is easy and in and creates mutation to improve their parameters. The efficiency of mutant production depends on many conditions such as $\mathrm{pH}$, soaking into water, temperature, concentration of azide and treatment duration. It creates point adverse conditions. Induced mutations have great potentials and served as a complimentary approach in genetic improvement of crops [13]. Various mutagenic agents are used to induce favourable mutations at high frequency that include ionizing radiation and chemical mutagens [13]. Induced mutations have been used to improve major crops such as wheat, rice, barley, cotton, peanut and cowpea, which are seed propagated. A number of workers have reported on the role of chemical mutagens in enhancing variability in higher plants. The mutants so produced facilitate the isolation, identification and cloning of genes used in designing crops with improved yields, increase stress tolerance, longer shelf life and reduced agronomic input $[14,15]$. Tomato suffers from several problems that include high disease incidence, pest infestations, and adverse effects of environmental stress that greatly affects its production. The results of a study on the effectiveness of Sodium Azide in inducing mutations in tomato are presented.

\section{Methods}

\subsection{Study Area}

The research was conducted in the Green House of the Science Laboratory Technology in The Oke Ogun Polytechnic, Saki, Oyo State which is located $8^{\circ} 40^{\prime} \mathrm{N} 3^{\circ} 24^{\prime} \mathrm{E}$ and it is situated at elevation 472 meters above sea level. Saki has a population of 178,677 making it the third biggest city in Oyo. It operates on the West African Time zone, which means that it follows the same time zone as Ibadan.

\subsection{Sources of Seed collection}

Seeds of cultivated tomato was obtained from the Institute of Agricultural Research (I.A.R\&T), Ibadan, Oyo State.

\subsection{Treatment Procedures}

2.6 Gram of Sodium Azide pellet was weighed into the petri dish based on the calculation of the molecular mass of Sodium Azide (65) and it was mixed with $100 \mathrm{ml}$ of distilled water. By using the protocol according to [16] containing the Tomato seeds were soaked in the beaker mixture of Sodium Azide, distilled water and 10ml of Phosphate Buffer Solution for 4 hours. The control was soaked in a beaker containing distilled water and 10ml of Phosphate Buffer Solution (the phosphate buffer solution is to reduce the acidic content of the solution). The seeds were thoroughly rinsed with running water from tap water after 4 hours in order to remove excess of the mutagens, then this was air dried at room temperature for 24 hours before planting.

\subsection{Planting Operation}

The treated seeds of tomato were planted in plastic containers containing $4.2 \mathrm{~g}$ of weighed humus soil in the Green House at the Department of Science Laboratory Technology of The Oke Ogun Polytechnic, Saki Oyo State. Four plastic containers with soil were mixed with organic matters (poultry dung) and also four plastic containers with soil were mixed with inorganic matters (NPK) of the same measurement.

\subsection{Data Collection}

Data was obtained for seedling height, the stem length, diameter of the fruit size, the number of leaf, the $\mathrm{pH}$ (Potential of Hydrogen), Nitrogen, Phosphorus, Potassium, Magnesium, Sodium, Iron, Sulphate, Calcium content were determined according to the procedures. 


\subsubsection{Seedling Height}

The height of the plant per treatment was determined after two weeks of planting by holding the highest leaf erect and the height measured in centimeters by the use of rulers/tape.

\subsubsection{Number of Leaf per plant}

The number of leaves produced per plant was counted and recorded for each treatment after the emergence of the first sprout.

\subsubsection{The Stem Length}

The stem length was determined per treatment by measuring the stem from the emergence of the root to the first flower produced in centimeter.

\subsubsection{Diameter of the Tomato Fruits}

The fruits diameter was measured after the production of first fruit per treatment in centimeter at after 46 days.

\subsubsection{Micro Nutrient in the soil}

The Nitrogen, Potassium, Phosphorus, Calcium, Sulphate, Sodium, Iron contents was determined for pre planting and post planting in experimental and the control.

\subsection{Data Analysis}

All the data obtained was analyzed using analysis of Variance and the mean was separated using Duncan's Multiple Range Test (DMRT).

\section{Results}

Table 1 Mean effects of Sodium Azide concentration on growth patterns of Tomato.

\begin{tabular}{|l|l|l|l|l|l|}
\hline S/N & Samples & Stem lengths & Leave length & No of leave & No of branches \\
\hline 1 & TSI & $14.26 \pm 0.52$ & $8.17 \pm 0.90$ & $50.76 \pm 0.78$ & $7.80 \pm 0.09$ \\
\hline 2 & TSO & $15.77 \pm 0.64$ & $8.30 \pm 0.90$ & $55.93 \pm 0.78$ & $7.62 \pm 0.09$ \\
\hline 3 & TSI & $10.76 \pm 0.52$ & $8.07 \pm 0.12$ & $48.11 \pm 0.71$ & $6.80 \pm 0.08$ \\
\hline 4 & TSO & $18.88 \pm 0.72$ & $9.00 \pm 0.10$ & $59.36 \pm 0.78$ & $7.35 \pm 0.09$ \\
\hline
\end{tabular}

Note: TSI - Tomato with SA with Inorganic; TSO - Tomato with SA with Organic; TSI - Tomato without SA with Inorganic; TSO - Tomato without SA with Organic

Table 2 The Chemical Constituents of the sample

\begin{tabular}{|c|c|c|c|c|c|}
\hline SAMPLES & 1 & 2 & 3 & 4 & 5 \\
\hline Sulphate (ppm) & 6.63 & 6.58 & 8.66 & 5.72 & 6.92 \\
\hline Calcium Ca (ppm) & 2.36 & 9.0 & 10.5 & 14.3 & 0.96 \\
\hline Sodium $\mathrm{Na}$ (ppm) & 0.79 & 0.86 & 0.80 & 1.04 & 0.77 \\
\hline Magnesium mg *100 (ppm) & $\begin{array}{l}1.44 \\
\text { Medium }\end{array}$ & $\begin{array}{l}4.5 \\
\text { high }\end{array}$ & $\begin{array}{l}6.25 \\
\text { Very high }\end{array}$ & $\begin{array}{l}0.60 \\
\text { Low }\end{array}$ & $\begin{array}{l}0.05 \\
\text { Very low }\end{array}$ \\
\hline Iron Fe ( ppm) & $\begin{array}{l}0.92 \\
\text { Very low }\end{array}$ & $\begin{array}{l}3.97 \\
\text { low }\end{array}$ & $\begin{array}{l}4.44 \\
\text { Medium }\end{array}$ & $\begin{array}{l}1.42 \\
\text { Very low }\end{array}$ & $\begin{array}{l}1.57 \\
\text { Very low }\end{array}$ \\
\hline $\mathrm{pH}$ value & 8.3 & 8.1 & 8.3 & 8.2 & 8.2 \\
\hline
\end{tabular}


Table 3 Composition of N, P, K of the sample

\begin{tabular}{|l|l|l|l|}
\hline & Nitrogen & Phosphorus & Potassium \\
\hline TSO & L2 (Low) & M1 (Medium) & M2 (Medium) \\
\hline TSI & L1 (Low) & M1 (Medium) & M1 (Medium) \\
\hline TSO & M1 (Medium) & M2 (Medium) & M1 (Medium) \\
\hline TSI & L2 (Low) & L2 (Low) & M2 (Medium) \\
\hline Control & $\begin{array}{l}\text { Nitrogen } \\
\text { L1 (Low) }\end{array}$ & $\begin{array}{l}\text { Phosphorus } \\
\text { M1 (Medium) }\end{array}$ & $\begin{array}{l}\text { Potassium } \\
\text { M1 (Medium) }\end{array}$ \\
\hline
\end{tabular}

\section{Discussion}

\subsection{Mean effect of Sodium Azide concentration on growth characters of Tomato}

The result of this work showed that all the traits studied were affected by sodium azide treatment. The decrease in seedling emergence, seedling height, root length, and seedling survival, height at maturity and fruit yield per plant with increasing mutagen concentration has been reported in mutagenesis studies [11] when groundnut was treated with gamma rays. The effects of ionizing radiation on tomato also revealed that these traits were dose dependent [11]. Similar result was obtained by [13] when gamma rays [14] similarly showed that all plant mutant types registered lower yields compared to their parents in the study of the effects of diethylsulphate and EMS on Okra (Abelmoschus esculentum (L.) var. MDU-1). Generally, sodium azide was very effective in inducing mutations with respect to germination percentage, root length, seedling height, seedling survival, number of branches per plant, and yield per plant in tomato. The most effective concentration being $4.0 \mathrm{mM}$. All the samples similarly responded to treatment differently with T106 being most stable. Sodium Azide therefore could be utilized to increase variability in tomato that ultimately increases the possibility of isolating beneficial mutants for improvement of tomato production.

The generation indicated study in the significant difference for all traits studied in the tomato grown with organic and inorganic fertilizer exposed to sodium azide. There was general decrease in germination percentage, seedling height, number of leaves per seedling, height at maturity and fruit yield per plant in tomato exposed to Sodium Azide but there was increase in the plant survival in tomato exposed to Sodium Azide. Compare to tomato grown with inorganic, tomato grown with organic shows significant increase in seedling height, leaf length, number of branches, number of leaves and also shows high plant survival rate

The result in table 1 showed that the stem length was ranged from $18.88 \pm 0.72$ and $10.76 \pm 0.52$ with sample of tomato with and without sodium azide with organic had the highest stem length value and tomato without sodium Azide and

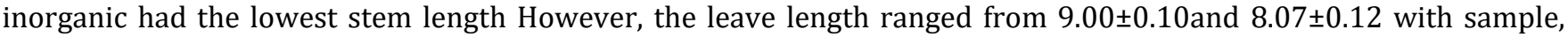
tomato without and with Sodium Azide \& Organic had the highest leave length and sample of tomato without Sodium Azide and inorganic had the lowest value The table also showed that number of leave ranged from $55.93 \pm 0.78$ and 48.11. \pm 0.71 with sample of tomato with sodium azide with organic had the highest while the tomato with sodium azide \& Inorganic had the lowest number of leaves, However the number of branches ranged from $7.80 \pm 009$ and $6.80 \pm 008$ with Sodium Azide and inorganic with the highest value and tomato without Sodium Azide and inorganic with the lowest value.

Table 2 shows that tomato grown with organic fertilizer both with Sodium Azide and without have high content of sulphur, nitrogen, phosphate, potassium, calcium, magnesium and iron compare to the tomato grown with inorganic fertilizer. It also shows that the $\mathrm{pH}$ value is moderately alkaline.

\section{Conclusion}

The study was conducted to ascertain the effects of mutation via Sodium Azide on tomato. Induced mutation using various concentrations of Sodium Azide were employed singly and in combination with organic and inorganic with the 
aim of improving the growth and yield parameters of the plants in both the wet and dry seasons. Significant improvements were found among the mutant tomatoes. There was significant difference in the effect of Sodium Azide and grafting on the growth and yield components of the three tomato varieties under study.

Further cytological and molecular researches should be taken on the improved tomato cultivars to further clarify the genetic bases of these beneficial methods of improvement.

Further researches should be embarked upon other mutants and tomato to test for stability to disease and stress tolerance.

\section{Compliance with ethical standards}

\section{Acknowledgments}

Special mention is made of staff of the Institute of Agriculture Research, (I.A.R\&T), Ibadan, Oyo State for timely analysis of the data of this study.

\section{Disclosure of conflict of interest}

The authors declared no conflict of interest during the research and envisage none would exist thereafter

\section{References}

[1] Julel DR. Starch grain and phytolith evidence for early ninth millennium B.P. maize from the Central Balsas River Valley, Mexico. PNAS. 2017; 106(13): 5019-5024.

[2] Viskelis JK, Akomeah PA, Ekpekurede EO. Gamma Irradiation Induced Variation of Yield Parameters in Cowpea (Vigna unguiculata) (L.) Walp.) Global Journal of Pure and Applied Sciences. 2015; 11(3): 327-330.

[3] Paven Blanco C, Aarts MG, Bentsink L, Keurentjes JJ, Reymond M. What has natural variation taught us about plant development, physiology, and adaptation? The Plant Cell. 2009; 21: 1877-1896.

[4] Bodunde M. Current situation of tomato grafting as alternative to methyl bromide for tomato production in the Mediterranean region Annual international research conference on methyl bromide alternatives and emissions reductions San Diego, CA USA. 2015; 1 -7.

[5] Adamu AK, Oluranju PE, Bate JA, Ogunlade OT. Radio-sensitivity and effective dose determination in groundnut (Arachishypogaea L.) irradiated with gamma-rays. Journal Agriculture and Environment. 2004; 3(1): 17-84.

[6] Dhahwal, Yan S, Okabe Y, Junming LI. Mapping of QTLs for drought tolerance during seedling stage using introgression line populations in Tomato. Acta Hort Sin. 2017; 38: 1921-1928.

[7] Perveen A, Gbate M, AN Umar. Medicinal and Economic Plants of Nupeland. Jube-Evans books and publications, Bida, Niger state. 2015.

[8] Akanbi MA. Use of Induced Mutations for Crop Improvement in Pakistan. In: Plant Mutation Breeding for Crop Improvement. 2007; 1: 67-72.

[9] Leonardi L, Romano VO. Recent advances in molecular breeding: the example of tomato breeding for favour traits. Acta Horticulture. 2004; 637: 231-242.

[10] Maruyama JP, Shennan C, Grattan SR. Developmental changes in tomato fruit composition in response to water deficit and salinity. Physiol. Plant. 2001; 83: 117-185.

[11] Adamu T, Shinozaki Y, Ezura H. Genes that influence yield in tomato. Breeding Science. 2002; 63: 3-13.

[12] Singh SM, Singh MA. Comparative analysis of genetic diversities within tomato and pepper collections detected by retrotransposon-based SSAP, AFLP and SSR. Theoretical and Applied Genetics. 2001; 110: 819-831.

[13] Sheeba T, Ariizumi T, Okabe Y, Asamizu E, d Hiwasa-Tanase K. TOMATOMA: A novel tomato mutant database distributing Micro-Tom mutant collections. Plant and Cell Physiology. 2005; 52: 283-296. 
[14] Saassi M, Langridge P Asamizu E, Hiwasa-Tanase K. Breeding technologies to increase crop production in a changing world. Science. 2005; 327: 818-822.

[15] Shen A, Abumalarmalhi J, Babu S, Ibrahim SNM. Mutagenic effects of gamma rays and EMS in M1 generation in sesame. Resources on Crops. 2003; 6(2): 300-306.

[16] Kuashik RR, Zaman-Allah M, Sreenivasulu N, Trethowan R, Varshney RK. Integrated genomics, physiology and breeding approaches for improving drought tolerance in crops. Theoretical and Applied Genetics. 2011; 125: 625-645.

[17] Mehandjiev SA, Akinnifesi FK, Sileshi G, Ajayi OC. Rootstock growth and development for increased graft success of mango (Mangifera indica) in the nursery. African Journal of Biotechnology. 2001; 9(9): 1317-1324.

\section{Author's Short Biography}

Mr. Adeoti Olatunde is member of learned societies and corporate organization with
some distinguished academic laurels. He is a senior Lecturer at the Oyo State Polytechnic,
Saki in the Department of Science Laboratory Technology. He is the leading figure in
Biology Unit. He has authored 50 peer reviewed international journal articles which
spanned across the field of Biology.

